\title{
Evaluate of Chill Vent Performance for High Pressure Die-Casting Production and Simulation of Motorcycle Fuel Caps
}

\author{
Piyanut Meethum $^{1}$ and Chakrit Suvanjumrat ${ }^{2,3}$ \\ ${ }^{1}$ Department of Mechanical Engineering, Faculty of Engineering, Siam University, Bangkok, 10163, Thailand \\ ${ }^{2}$ Department of Mechanical Engineering, Faculty of Engineering, Mahidol University, Salaya, Nakorn Pathom, 73170, Thailand \\ ${ }^{3}$ Laboratory of Computer Mechanics for Design (LCMD), Department of Mechanical Engineering, Faculty of Engineering, Mahidol University, \\ Salaya, Nakorn Pathom, 73170, Thailand
}

\begin{abstract}
Inappropriate air vent design always induced porosities in thin and complex shape of high pressure diecasting (HPDC) products. Chill block installation was preferred to improve permanent molds for reducing porosities. There were not regular to obtain an appropriated chill vent from this method unless an experience of mold makers. This research was performed to investigate and evaluate the chill block performance in the HPDC mold of motorcycle fuel caps. The HPDC mold of the thin and complex shape product without chill vents was improved by inserting of chill blocks. The motorcycle fuel caps of molds with and without chill vents were compared to verify size and position of porosity defects. Furthermore the HPDC simulation using the finite element analysis (FEA) had been performed according to the physical experiment. The FEA results were compared and in agreement with the experimental data. Therefore an improvement of the HPDC mold should be used FEA to obtain the best way of the air vent design.
\end{abstract}

\section{Introduction}

The gas entrapment during high pressure die casting (HPDC) processes always induces porosity occurring in many products [1]-[3]. The thin and complex shape of products had more occasion to meet porosities on its surface [4]. The causes ofporosity might be formed by unsuitable gate, runner, overflow and vents design [5,6]. Reduction of porosities in parts could start with an original design of runner geometry [7]. Chill block installation is the additional air- or gas-vent for permanent HPDC molds after usage and porosity detecting [8]. The efficiently exhausting residual air from the inside to the outside of mold cavity is mean by chill vent features. Unfortunately, there are destitute technique papers to use chill blocks then the mold maker has to use experience for the chill block selection.

Nowadays, computer-aided engineering (CAE) is an advance technology to design the HPDC product. The porosity in HPDC products could be assumed from the gas entrapment phenomenon using finite element analysis (FEA) [9]-[12]. Porosity could be reduced by optimization shapes of runner, gating systems or process parameters [13]-[15]. The FEA not only uses for design but also advances to improve permanent molds. Effects of the chill block installation could be simulated to determine a suitable shape and size of chill blocks.

This research attempted to use FEA to specify the chill vent performance. The simulated results were compared with experimental data and evaluated accuracy of simulation techniques. The procedure from simulation of the HPDC process will be used to improve further HPDC parts which have thin and complex shape for better surface quality.

\section{HPDC experiment}

Mold cavity of motorcycle fuel caps had been design with the important feature comprised of gate, runner and vent system. The chill block was inserted to increase zigzag profile chill vents inside an original mold with width, length, height, pitch and gap thickness of 45, 95, 8, 9 and $1 \mathrm{~mm}$, respectively (Fig. 1). The die-casting machine model TOYO-350T was employed to cast fuel caps with ACD12 alloy. The HPDC process was setup an accumulator pressure of $12 \mathrm{MPa}$, an injection high speed of $2.3 \mathrm{~m} / \mathrm{s}$, an aluminum temperature of $660{ }^{\circ} \mathrm{C}$ and a mold temperature of $120^{\circ} \mathrm{C}$.

Sampling of HPDC parts which is removed from the original mold cavity is shown in Fig. 2. Some features of the HPDC part such as vents were broken while removing from its mold therefore the HPDC part not had completely components as same as mold cavity. Small porosities were observed distinctly on surface of motorcycle fuel caps. The interesting porosities on surface of a left side cap of a symmetry HPDC part was closed by circles (A-, B- and C-circle). The scanning electron microscope (SEM) was employed to reveal characteristic of porosities. Micrographs of porosities in 
A-, B- and C-circle are shown in Fig. 3. Defects were deep then it was seen as a dark hole. The maximum length of porosity in A-, B- and C-circle was measured which obtained $0.278,0.374$ and $0.188 \mathrm{~mm}$, respectively. The HPDC part of the improved mold is shown in Fig. 4. Porosities still appeared on same positions of the original mold but the characteristic of porosities had changed. The porosity on an improved part was shallow more than an unimproved part and could not specify the maximum porosity length in A-, B- and C-circle. Fig. 5 shows the micrograph of porosities on a HPDC part of the improved mold.
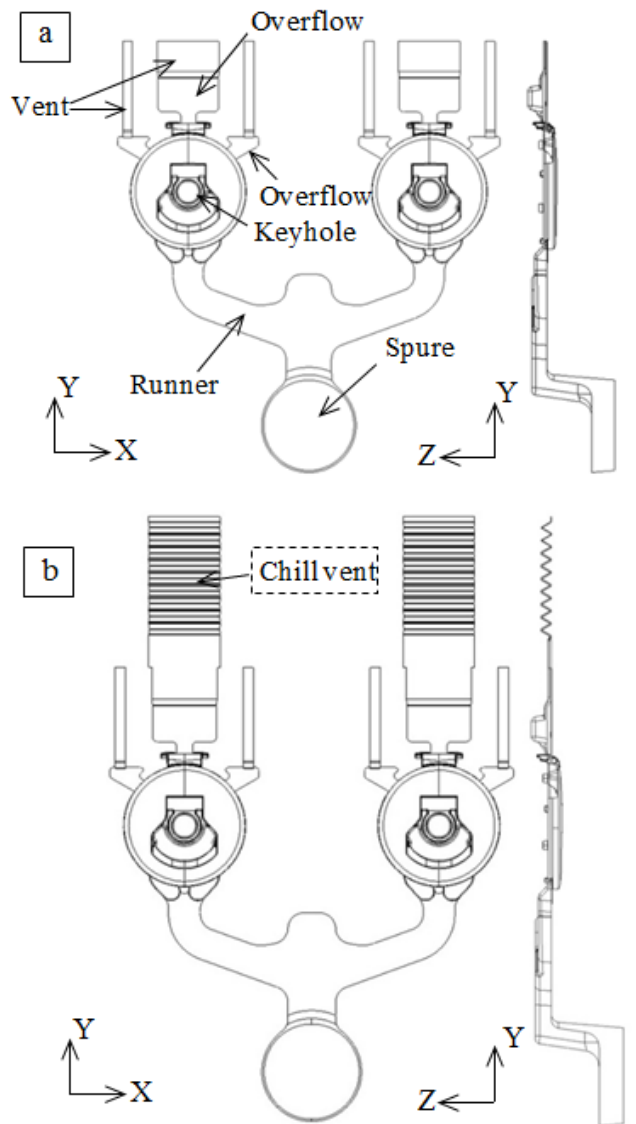

Figure 1. Motorcycle fuel caps of: (a) an original mold cavity and (b) an improved mold cavity.

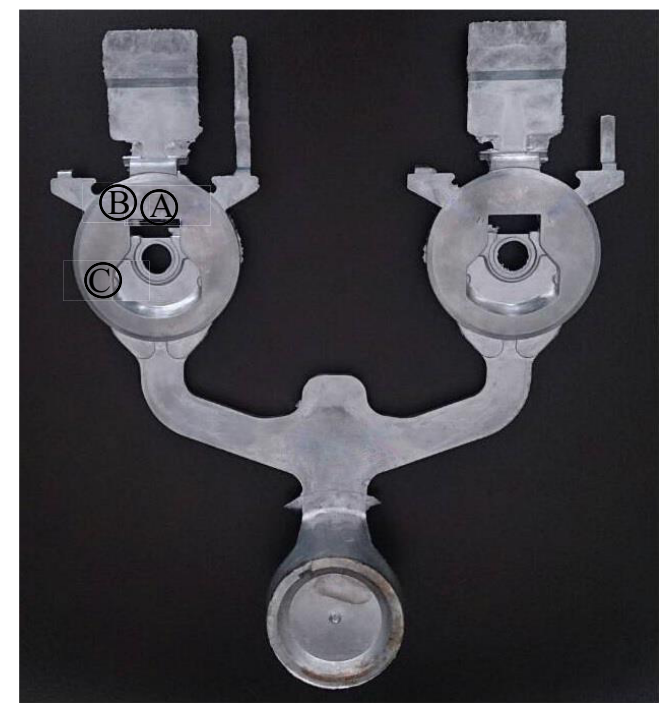

Figure 2. Motorcycle fuel caps of an original HPDC part.
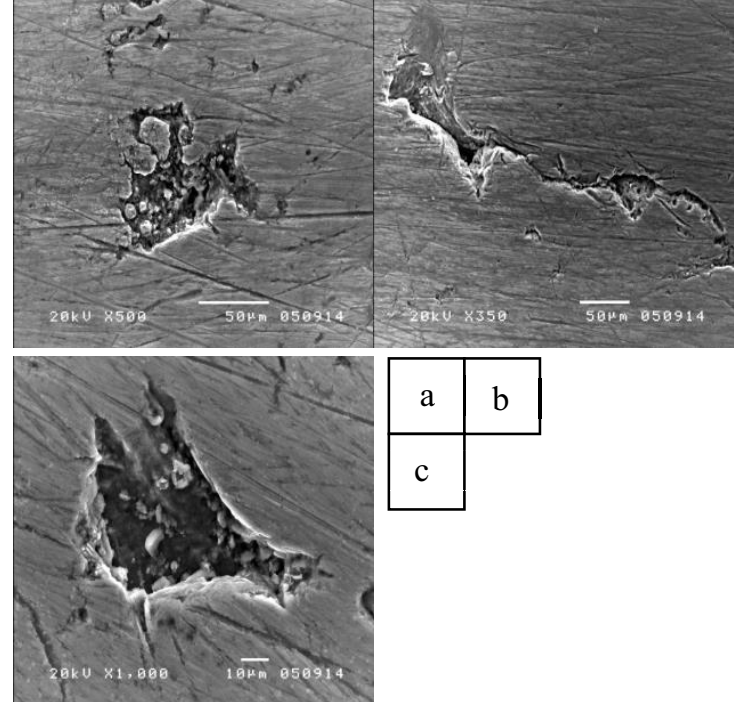

Figure 3. Porosity in: (a) A-circle, (b) B-circle and (c) C-circle on an original HPDC part.

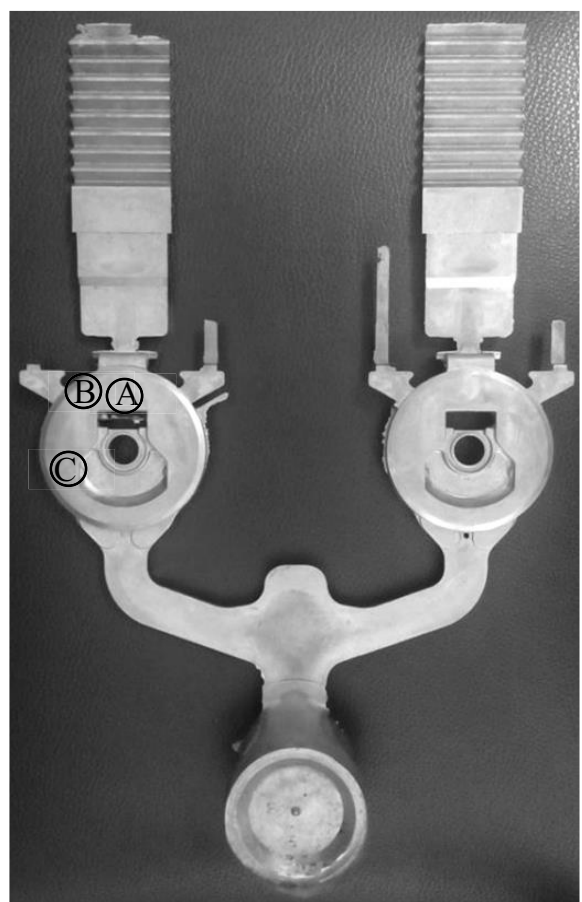

Figure 4. Motorcycle fuel caps of an improved HPDC part.

\section{HPDC simulation}

Mold cavity for producing motorcycle fuel caps in the previous section was modeled by computer aided design (CAD) software, SolidWorks version 2011. Subsequently, the mold cavity model was exported for the standard file, stp file, to use in the CAE software, CASTDESIGNER software, to create finite element (FE) model. The FE model was test convergence of results of mesh quantity. The 413,615 and 469,320 hexahedral elements are used to divide the cavity model and the FE model is shown in Fig. 6. The maximum size of elements was 1.0 $\mathrm{mm}$ which far away from an interesting area. The smallest element which had size about $0.7 \mathrm{~mm}$ was controlled to locate around the keyhole of the motorcycle fuel cap. The material property of molten aluminum was 
defined into the FE model as same as the experiment data. Boundary conditions such as the injection high speed and the aluminum temperature were specified on the FE model also according to the HPDC process parameters. The personal computer with Core-i5 CPU and RAM memory of $4 \mathrm{~GB}$ was used to perform the HPDC simulation.
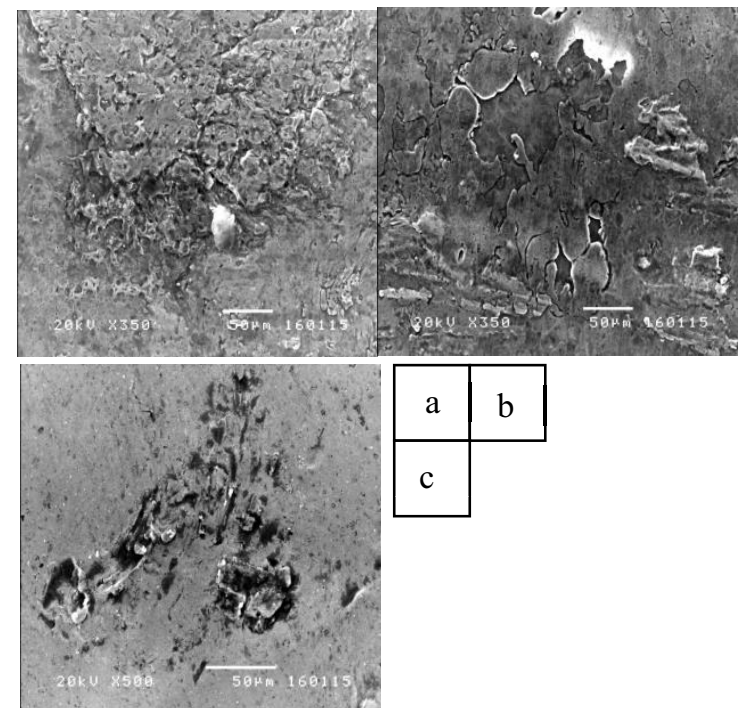

Figure 5. Porosity in: (a) A-circle, (b) B-circle and (c) C-circle on an improved HPDC part.

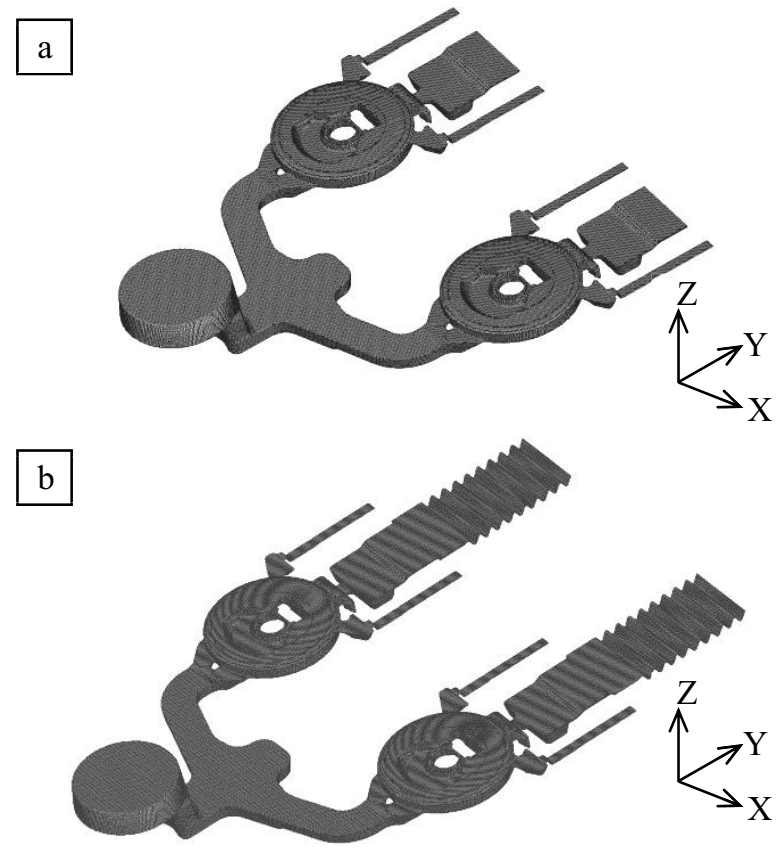

Figure 6. The finite element model of: (a) an original mold cavity and (b) an improved mold cavity of motorcycle fuel caps.

\section{Results and discussion}

The sequent images of molten aluminum filling into mold cavities of the original and improved mold are shown in Fig. 7 and Fig. 8, respectively. The molten aluminum velocity was illustrated by a color contour. The maximum velocity was signified by red and minimum velocity was blue. The unfilled space occurred at twelve o'clock position of a left and right cap cavity caused molten aluminum velocity reduced to zero around key hole. This area had many ribs to obstruct molten aluminum flow therefore was risk to occur an air entrapment phenomenon which induced porosities happened on surface of the motorcycle fuel cap. Porosity defects occurred after motorcycle fuel caps fully filled with molten aluminum in the filling time of $0.03 \mathrm{sec}$. Final points of porosity in mold cavities are indicated by shape of black volumes as shown in Fig. 9. The simulation results were distinct porosity location of porosities typically occurred on a left and right cap of the original and improved mold cavity of FE model. The maximum size of porosities in A-, B- and C-circle on the original and improved mold cavity are regarded to compare with the experiment data. The maximum size of porosities in circles A, B and C reduced from $0.383,0.499$ and 0.465 to $0.358,0.469$ and $0.433 \mathrm{~mm}$, respectively. Even though the porosity was not eliminated from fuel caps by improvement of the HPDC mold, it could be easy to remove by polishing process.

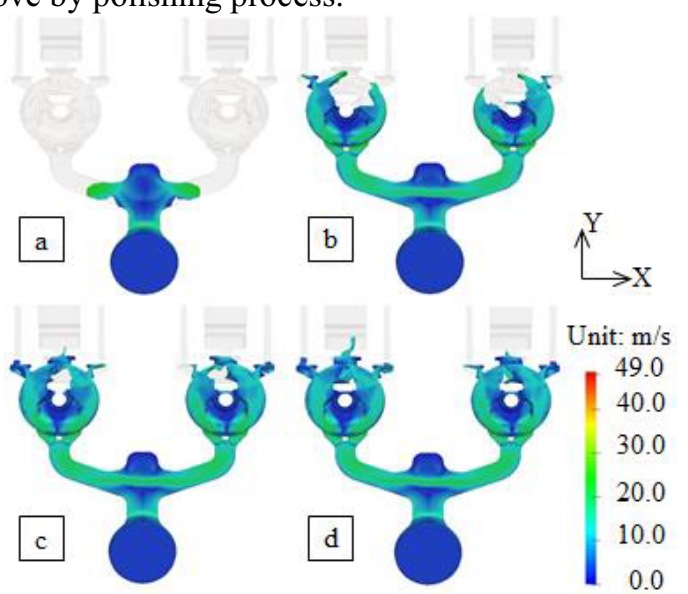

Figure 7. Sequent images of molten aluminum filling into an original mold cavity at: (a) 0.014 , (b) 0.020 , (c) 0.022 and (d) $0.024 \mathrm{sec}$.

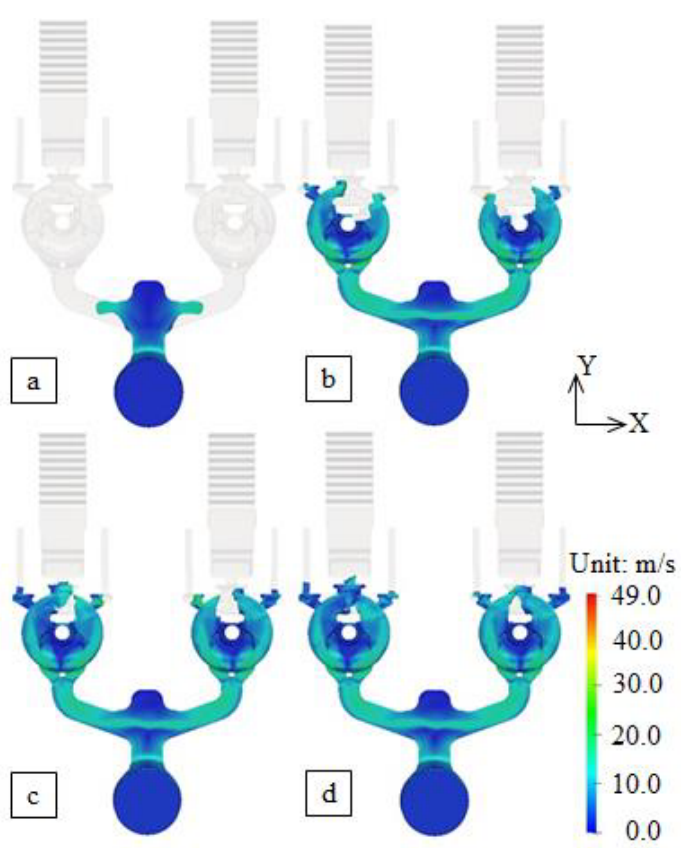

Figure 8. Sequent images of molten aluminum filling into an improved mold cavity at: (a) 0.014 , (b) 0.020 , (c) 0.022 and (d) $0.024 \mathrm{sec}$. 


\section{Conclusions}

The HPDC mold had unsuitable air vent was used to produce aluminum fuel caps therefore porosities occurred on surface nearly the keyhole. CAST-DESIGNER which was FEA software was used to simulate the HPDC process. The FEA results illustrated the keyhole of fuel cap obstructed flowing path of the molten aluminum therefore it induced porosities on the motorcycle fuel cap surface where the molten aluminum could not flow. The porosity defects of FEA results had locations in agreement with the experiment data. The maximum size of simulated porosities was compared with experiments obtained the average different length of $0.169 \mathrm{~mm}$ on the original HPDC part. Porosity was reduced at an average size of $6.47 \%$ when chill blocks were inserted in the original mold. The comparison confirmed an accuracy of the HPDC software therefore the setting parameters of the simulation will be useful for the improvement of fuel cap molds. The appropriate shape of fuel caps under a comfortable flow of molten aluminum will be considered with design in further works.

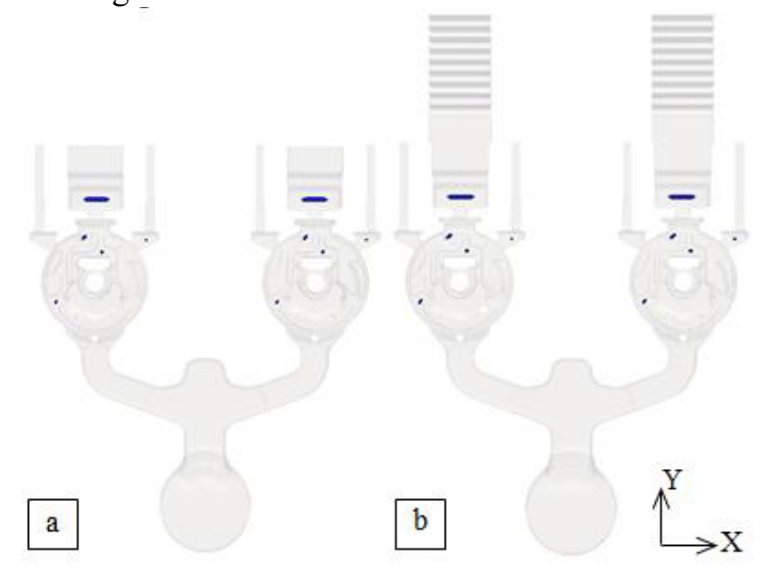

Figure 9. Images of porosity on surface of: (a) an original and (b) improved HPDC part.

\section{Acknowledgement}

This research was funded by The Thailand Research Fund (TRF) and Micro Precision Co., Ltd under Research and Researchers for Industries (RRI): Master Degreegrant no. MSD57I0137. The CAST-DESIGNER software had permitted for using a license by 4D Corporation Ltd.

\section{References}

1. Y. Hangai, S. Kitahara, Mater. Design 30 (2009)

2. J.J. Hernandez-Ortega, R. Zamora, J. Lopez, F. Faura, Int. J. Adv. Manuf. Technol. 67 (2013)

3. A. Wilczek, P. Dlugosz, M. Hebda, J. Nondestruct. Eval. 34 (2015)

4. E. Aghion, N. Moscovith, A. Arnon, Mat. Sci. Eng. A 447, 341 (2007)

5. S.G. Lee, A.M. Gokhale, G.R. Petal, M. Evans, Mat. Sci. Eng. A 427, 99 (2006)

6. L. Wang, P. Turnley, G. Savage, J. Mater. Process. Tech. 211, 1510 (2011)

7. R. Malterer, US Patent 0016710A1. (2005)

8. D.R. Gunasegaram, M. Givord, R.G. O’Donnell, B.R. Finnin, Mat. Sci. Eng. A 559, 276 (2013)

9. H.D. Zhao, F. Wang, Y.Y. Li, W. Xia, J. Mater. Process. Tech. 209 (2009)

10. H.D. Zhao, Y.F. Bai, X.X. Ouyang, P.Y. Dong, T. Nonferr. Metal. Soc. 20, 2064 (2010)

11. C.K. Jin, C.H. Jang, C.G. Kang, J. Mech. Sci. Technol. 27, 10 (2013)

12. O. Boydak, M. Savas, B. Ekici, Int. J. Metalcasting 10, 1 (2016)

13. C. C. Tai, J.C Lin, J. Mat. Process. Tech. 84 (1998)

14. R. Singh, R. Kapoor, J. Inst. Eng. India Ser. C 94, 2 (2013)

15. B.V. Ramnath, C. Elanchezhian, V. Chandrasekhar, A.A. Kumar, S.M. Asif, G.R. Mohamed, D.V. Raj, C.S. Kumar, P. Mat. Sci. 6, 1312 (2014) 